\title{
EFFECT OF COVID-19 ON POULTRY INDUSTRY: IS THERE AN OPPORTUNITY FOR MORE SUCCESS?
}

\author{
Nessrin A. Selim \\ Poultry Nutrition Research Department, APRI, ARC, Egypt. \\ nessrinselim@gmail.com
}

SUMMARY

\begin{abstract}
lobal and local poultry industry have affected by COVID-19 global pandemic and consequence 7 periods of quarantines especially in 2019/20 in many countries. The quarantines' periods, lockdowns, self- isolation of workers and death rate have disrupted both supply chain and value chain of poultry industry. As a result, there are different governmental strategies had reported to decrease the effect of that economic crisis on poultry industry on both production and consumption levels. In Egypt, poultry production mainly depends on imported feed raw materials, feed additives, vaccines, veterinary supplies, and production equipment's. Consequently, availability, quality and prices of production inputs are greatly affected by pandemic effects on supplying countries. Furthermore, there is variation of recorded pandemic effect on poultry producers according to many factors, while small holders are the most negatively affected farmers due to different reasons. Although there are many reports focused on either the negative impact of COVID-19 on poultry industry and human food security, or the potential spread of virus within workers in poultry slaughterhouses, there is still a chance to create a positive opportunity to record more success and sector development based on pandemic consequences. This report spotlights on some global changes and emergency strategies to minimize the impact of pandemic on poultry production. Also, it introduces some local governmental responses to face the fluctuation in both prices and availability of inputs, safety of raw materials and sustain the suitable consumers' demand. Finally, the report introduces an example of creation of additional success story from market challenges.
\end{abstract}

Keywords: Poultry industry, COVID-19, pandemic effects,

\section{INTRODUCTION}

However, COVID-19 pandemic has affected on poultry production globally, the reported effects depended on countries' advantage and their satisfaction level of production. The supplying countries of raw materials, feed additives, and veterinary products suffered from labor limitation, increase cost of staff medical assurance, and lockdown periods which disrupted their production cycle, operating expenses, and distribution chain. These countries could maintain acceptable level of human food security including poultry products during the pandemic, especially during lockdown periods, with acceptable increased prices due to change of market supply and demand. On the other side, the demand countries (developing and third world countries) faced more severe limitation of production inputs because of supply chain disorder in addition to the mentioned problems (Sharma et al. 2021).

In addition, countries with high population and absence of public previous experience about respiratory pandemic, like Egypt, faced more difficulties to establish public awareness of prevention and isolation. Workers in poultry production facilities have exposed to increased probability of infection due to either potential exposing to higher levels of NH3 in poultry farms, or shorter distance between work team in poultry slaughterhouses. Under all those risky and stressed conditions, the production of poultry continued to cover the increased demand of poultry products during the first months of the crisis. Previous reports showed fluctuated changes in price of poultry products. While price of poultry meat increased during first weeks of crisis followed by decreasing, price of eggs increased dramatically by prolonged lockdown period in many countries (ANCO, 2020; AVEC, 2020; and NFU, 2020). Those challenges-oriented governments to create and implement different strategies to decrease the impact of the pandemic and protect poultry production from huge changes and to maintain acceptable food security levels from poultry products. Also, the workers in poultry production (producers, researchers, investors,

Issued by the Egyptian Society of Nutrition and Feeds 
and NGOs) have additional tasks and responsibilities to protect the local and global production against economic impact of COVID-19.

\section{Global emergency strategies}

Generally, governments followed different emergency strategies to decrease effect of COVID-19 on poultry sectors such as subsidization of raw materials, financial aids, low interest loans, decreasing taxation and enhance safety of labor working conditions (FAO, 2020), according to both the classification of poultry producers and the effect of the pandemic on each related country (Uyanga et al., 2021). Durand-Moreau et al. (2020) presented different causes of COVID-19 transmission between workers in feed mills, farms, and slaughterhouses. Dyal et al. (2020) mentioned that the greatest \% of infected labors was in slaughterhouses due to many reasons. As difficulty of saving a $2 \mathrm{~m}$ of physical distance between workers in several points in operation areas especially whereas processing hall conditions (temperatures, 4 to $6^{\circ} \mathrm{C}$; relative humidity rates, $>50 \%$, and stainless-steel surfaces) are suitable to maintain COVID-19 virous a life for longer time. CNN, 2020 supported the same conclusion about high risks in poultry processing plants due to limited area, climatic conditions, and unsustainable payment for workers. Furthermore, some workers were not covered their faces well during working time according to American Centers for Disease Control and Prevention report. While the bad housing conditions and language difficulties of immigrant labors were the main reasons of spread infection between farm workers in some countries like Germany, Ireland, Canada, and USA. These poor housing and working conditions of immigrant labors were reported earlier by Human Rights Watch (2019), so COVID-19 pandemic could reactivate the role of International Labor Organization to guarantee suitable working conditions and labor health care programs Durand-Moreau et al. (2020). Generally, the bad and crowded housing conditions of poultry labors were clearly appeared in other countries worldwide after required physical social distancing to restrict COVID-19 transmission. Another direction has shown by Clements (2020b) while reported that over $14 \%$ of respondents to the study in UK and Spain revealed that the pandemic had rejuvenated a switch to fully automatic slaughtering plants. Regarding to UK, post-Brexit immigration laws add 5,500 poultry workers to existing visa schemes which interrupted the poultry farms due to return of immigrant labors to their countries in EU. That directed NFU and the UK government to issue a permanent seasonal worker plan (visa for 12 months) for sustainable agriculture and poultry production including fast visa processing and better social conditions and study plan of training improving labor skills.

A different protective strategy was announced in Argentina where poultry meat consumption was 46 $\mathrm{kg}$ per capita in 2020. That developed consumption rate directed the Argentina's central bank, BCRA, offered a $30 \%$ financial discount for poultry companies regardless of their size aiming to increase internal market satisfaction and export growth of poultry products (Azevedo, 2021).

In Bangladesh, Poultry sector include 8.5 million workers and includes different types of production (backyard, traders of native and exotic breeds). During the closing period the overall feed production decreased by $40 \%$ due to holding supply and distribution chains. And the government \& NGOs introduced some financial aids for small holders (including rural producers) for facing the great increase of input materials and DOC, while other producers asked the government to decrease the import taxes as a compensation for the unforeseen circumstances during the pandemic (AlSattar, 2021). South Africa government followed the same way of introducing financial aids for poultry small holders to save some production input costs which improve their sustainability of production (South Africa Government, 2020).

\section{Local Situation:}

The estimated value of total investments in poultry industry in Egypt was calculated at around USD 4.5 billion, which created (directly and related activities) 2.5 million employment opportunities Hattab, et al. (2021b). Broiler production represents the largest sector of poultry industry, with the production of broiler chickens in 2019 estimated at 1.8 billion birds, which cover $95 \%$ of the country's total poultry consumption (Mekled, et al., 2019). Hattab et al. (2021a) cleared that broiler production systems in Egypt are classified into three main categories: industrial production systems, small-scale commercial production systems, and backyard production systems (Tellioglu, and Konandreas, 2017). Statistics of Egyptian Ministry of Agriculture and Land Reclamation (MALR, 2019) showed that small-scale commercial systems (small holders) represents around 70\% of all poultry-producing farms in Egypt. That sector is subclassified to subclasses according to capacity, technology and produced strains. Generally, most of smallholders produce $5000 \mathrm{bird} /$ cycle with $4-5$ cycles/year, while some of them have increased 
farm capacity and production cycles/year. In addition, there are spread production unites in rural sector as household-based which produce small numbers of birds and cycles yearly (Calduch, 2013). The production in small-scale commercial systems is based on very traditional non automated model which make farmers gain lower profit because of poorer performance, high cost of production inputs and higher mortality rate of birds beside limitation/absent of technical scientific and economic background of producers.

Like other countries, all classes of intensive production suffered during closing period due to supply chain interruption, while the impact of that depended on the safety stock before lockdown starting. Breisinger et al. (2020) reported the initial size of economic shock of livestock sector due to COVID-19 (includes Cattle, dairy, poultry, and other livestock) by $10 \%$.

Also, most importers had limited capacity for storing all inputs especially cold storing materials (vitamin premixes, vaccines, and some veterinary medicines) and faced logistics problems of distribution chain (Hatab, 2021a). According to UNIDO assessment of the key bottlenecks in Egypt's food system and the impact of COVID-19 (UNIDO, 2020) and confirmed that poultry production (as other food production system) has affected by the pandemic due to the same previous reported factors (supply chain, labor, and financial problems). These conclusions were in match with report of Egyptian Association of Agricultural Economics (EAAE, 2020).

\section{A. Governmental responses}

Poultry products (meat, eggs, and their processed products) are main and preferred animal protein sources for Egyptians. So, the government gives poultry industry advantage priority to maintain sustainable production and consumption during the COVID-19 crisis and lockdown period. Therefore, there was no movement restriction for producers, farm workers, and related activities persons (Breisinger et al., 2020). Additionally, the Egyptian government implemented some emergency strategies as crisis response to eliminate the impact of the pandemic on the food security including poultry production.

\section{Organizing Responses}

- Mobility permission for trucks of poultry products and raw materials to sustain delivery from and to poultry farms and distribution centers.

- Develop procedures for registration of feed and feed additives with transfer to the online electronic system.

- Extending the duration of operation licenses of farms and poultry manufacturing facilities.

- Governmental decree of creating high committee for poultry industry development. The committee includes many ministries, poultry production association, experts, and trade chamber to study all challenges facing the industry and to update the governmental plan of converting of small holder model to full automated economic production model.

- Ministry of Agriculture Proposal to establish Council of Disease Control (CDC).

- $\quad$ Caring about food safety by establishing the National Food Safety Authority of Egypt (NFSA), which start to put KPIs of safety system of poultry products and related slaughterhouses, distribution channels, and marketing centers.

- Merge poultry meat and table eggs to list under the commodity exchange as a tool to identify the fair price for producers and suitable final price for consumers.

\section{Fiscal \& Financial responses}

- Decree of Egyptian Central Bank of postponing payment of previous loans interest for 6 months at the beginning of crisis in Egypt.

- Low interest loan (5\%) for poultry producers including small holders to change open system poultry houses to close system to increase sustainability level of production.

- $\quad$ Supporting liquidity of producers by $5 \%$ loans for operation supplies and operation expenses.

- $\quad$ Provide regular fiscal aids to seasonal workers affected by COVI-19 (Takaful and Karama).

\section{B. Private sector (Small-Scale Broiler farms).}

As described in local situation part, small-scale commercial systems (small holders) represents around $70 \%$ of all poultry-producing farms in Egypt. Many reports showed that the pandemic has worsened the economics of poultry farming and that most small-scale producers are on the brink of bankruptcy, experiencing capital shortages and fearing that they will not be able to continue their work due to interruptions in the livestock supply chain (Fan et al., 2020; and Hafez and Attia, 2020). Hatab et al. 
(2021b) identified three major causes of the negative effects of the pandemic on small-scale poultry producers as compared to larger producers. First, small-scale producers and firms in these countries rely more heavily on labor than on machinery, and, thus, their poultry production has been especially compromised by containment measures and lockdowns. Second, small-scale producers in developing countries have limited logistical and financial capacity to implement hygiene measures, which, in turn, increases their vulnerability to COVID-19 effects. Third, most small-scale agrifood-producing farms, including poultry farms, operate informally and, therefore, are excluded from the stimulus plans that governments have offered to private businesses.

Hatab et al. (2021b) introduced important study about recognizing the primary effects of COVID-19 on small-scale broiler producers (sample of 205 farms in Al Qalyubia governorate). The reported results showed many differences between farms in their management and production systems and resource endowment. All farms had affected by COVID-19 by interruption of supply chain, absence of workers, reducing the consumer purchasing power and demand and difficulty of paying all production liabilities. The individually owned farms and those with membership of poultry producer organizations and larger total asset values perceived fewer effects of pandemic. In addition, SCBFs operating in both local and provincial markets were less likely to perceive negative effects from the pandemic on their broiler farming activities. The results showed $61.5 \%$ of farms have less than 200,000 LE of total assets while only $21 \%$ has higher than 500000 total assets value. That reflected on the annual sales/farm, where $63.4 \%$ recorded less than 300000 LE. Although only $45.8 \%$ of farm workers received high university education, about $68 \%$ of farms recorded increases in the total cost of production and operation with by $20-40 \%$ while only $7 \%$ of farms maintain their operation cost. In my opinion, those records reflected difficulties of reducing operation cost in farms; even workers hold university education, due to absent of technical support which helps producers to decrease their operating cost especially with low assets farms. On the opposite situation, the industrial poultry production farms follow restricted disease control program and have the suitable high qualified staff, quality assurance system, high financial management which help their organization to gain more net profits according the implemented business plan. There is general evidence that workers in small-scale poultry farms need support their technical and administrated background to improve their ability to facing emergency crisis now and in future.

However the governmental liquidity support by $5 \%$ interest loans is very important to help small producers to continue in production pool, farm workers need to receive technical programs to improve their ability for enhance production KPIs (key performance indicators) and reducing operation cost. This situation put additional social responsibilities on industrial organizations and non-governmental organizations (NGOs) to improve KPIs in small-scale farms which help them to gain more net profit. Continuous technical follow up and support by broiler breeder companies (source of DOC), feed mills (source of feed), vaccine and medicines companies (source of vaccines and veterinarian products) are required. Application of governmental decision of commitment to veterinary supervision on the poultry farms can help producers to receive the desired technical support in area of diseases problem only.

\section{C-NGOs Responsibilities - Success Story}

There are many local poultry NGOs in Egypt including different categories according to their main targets. Scientific poultry NGOs are concerning with research about problems of poultry industry and reports valuable recommendations and sharing knowledge globally but lacks to effective marketing of research results. Poultry cooperatives NGOs are concerning with cooperative activities with poultry producers like introducing supplies and feed with affordable prices. The most organizing important poultry NGO is Egyptian Poultry Association, who established by law in 1998. EPA is concerning with studying problems of producers, encouraging investment in poultry sector, enhancing product specifications and marketing. EPA has extension activities for poultry companies and their high educated staffs through regular training programs for them under collaboration with internal and external academic and NGOs parties. Although, there is no training support for small-scale poultry worker, regardless their education level. That class of staff requires adapted and simplified scientific materials in mother language to be attractive and easy understanding by them. As there is expected long time of raised prices of raw materials according to regular reports of USAID, there is greater importance to give this task high priority. As a researcher and poultry expert, it is necessary to teach them the economic production model and how to improve their performance. If related NGOs succeeded in that mission, the small-scale poultry producers will record better feed conversion ratio (FCR) and mortality rate which will decrease the gap between records of industrial organization and them and increase their ability to pay the governmental loan interest and other liabilities. 
Among the current poultry NGOs, there is recent extension activity targeting low educated/ nonspecialized poultry workers and producers has introduced by Egyptian Poultry Improvement Society (EPIS). According to EPIS board through social media, they are concerning with all poultry producers and their production problems. EPIS put lower qualified poultry workers and producers priority to increase their performance and improve their production skills. The organization believe that the global changes will cause strongly effect on that class of poultry producers, so enhancing their ability to record net benefits is necessary to harvest results of the governmental supportive strategies for them. EPIS extension activity by complete package about nutrition, biosecurity, management, and economics which provide them with general frame of knowledge for sustainable production. If local poultry related NGOs focus on the same goal, the overall impact of COVID-19 on total poultry production in Egypt will minimize and the gross poultry production will increase. Consequently, the Egyptian food security level will be improved, and market prices of poultry products will show better records.

\section{Conclusion and recommendations}

However, the global poultry production has affected by COVID-19, the current local situation includes many governmental responses to keep the local industry. These put more responsibilities on all related parties (scientific, investors, NGOs, small producers, and customers) to contribute in protect the national industry against declining. If we make good use of organized decisions and work on the industry weaknesses, the result will be satisfied for all parties and future generations.

As the government already implemented emergency strategy to reduce effect of COVID-19 on poultry production, there is still some recommendations to focus on as:

- Implementation of Diseases Control Center (CDC) for controlling poultry settled diseases and create system of prevention unknown expected diseases according to long term strategy.

- Establish a package of incentives for smallholders to convert to vertical integrated system provided with high technical and management skills to decrease effect of any crisis in future on their production sustainability.

- $\quad$ Restudying tax of added value (14\%) on feed additives and its overall effect on feed cost and price of poultry product especially with current and near future global increase of production supplies.

- Organized NGOs extension activities which focus on most critical weakness in production like small holders' skills, nutrition strategy, economic management, and poultry health.

\section{REFERENCES}

A1 Sattar, A., R. Mahmud, Md. A. Mohsin, N.N. Chisty, Uddin, M.D. Nusrat Irin, T. Barnett, G. Fournie, E. Houghton and Md.A. Hoque (2021). COVID-19 Impact on Poultry Production and Distribution Networks in Bangladesh. Frontiers in Sustainable Food Systems $\mid$ www.frontiersin.org

Animal Nutrition Competence (ANCO). (2020) How are egg prices and egg producers responding to Covid 19. https://www.anco.net/howare-egg-prices-and-egg-producers-responding-to-COVID-19/.Accessed June 12, 2020.

Azevedo, D. (2021). Argentina: discounts offered on loans to poultry sector (2021) World poultry net.

Breisinger, C., M. Raouf, M. Wiebelt, A. Kamaly and M. Karara (2020). Impact of COVID-19 on the Egyptian economy: Economic sectors, jobs, and households. Report of: International Food Policy Research Institute (IFPRI).

Calduch, N.E.; S. Elfadaly, M. Tibbo, P. Ankers and E. Bailey (2013). Assessment of biosecurity practices of small-scale broiler producers in central Egypt. Prev. Vet. Med. 2013, 110, 253-262.

Clements, M. (2020b) Poultry around the world what-poultry-producers-are-saying-about-the- COVID -19outbreak. Accessed June 3, 2020 https://www.wattagnet.com/blogs/23-poultry-around-theworld/post/40146-

CNN (2020). 2 million chickens being killed because processing plants are short-staffed. https://www.thedenverchannel.com/news/national/coronavirus/2-million-chickens-being-killed-becauseprocessing-plants-are-short-staffed. Accessed June 21, 2020 
Durand-Moreau, Q., A. Adisesh, G. Mackenzie, J. Bowley, S. Straube and X.H. Chan (2020). COVID-19 in meat and poultry facilities: a rapid review and lay media analysisAccessed December 6, 2020

Dyal, J.W., M.P. Grant and K. Broadwater (2020). COVID-19 Among Workers in Meat and Poultry Processing Facilities - 19 States, April 2020. MMWR Morbidity and Mortality Weekly Report;69(18). doi:10.15585/mmwr.mm6918e3.

European Poultry Producers Association (AVEC) (2020). The impact of the COVID 19 crisis on the EU poultry $\quad$ sector. April 2020. https://pluimvee.be/src/Frontend/Files/Core/CKFinder/files/2020_04_21\%20The\%20Impact\%20of\%20th e\%20COVID-19\%20crisis\%20on\%20the\%20Poultry\%20Sector.pdf. Accessed June 20, 2020

EAAE (Egyptian Association of Agricultural Economics). (2020). An Analysis of the Impacts of COVID-19 Crisis on Food Security in Egypt, and the Policies and Measure to Address Its Consequences; EAAE Policy Paper (April 2020); EAAE: Cairo, Egypt, 2020.

Fan, S., W. Si and Y. Zhang (2020). How to prevent a global food and nutrition security crisis under COVID19? China Agric. Econ. Rev., 12: 471-480.

FAO. 2020. "Food and Agriculture Organization. Q\&A: COVID-19 Pandemic - Impact on Food and Agriculture.

http://www.fao.org/2019-ncov/q-and-a/en/.

Hafez, H.M. and Y.A. Attia (2020). Challenges to the poultry industry: Current perspectives and strategic future after the COVID-19outbreak. Front. Vet. Sci., 7: 516.

Hatab, A.A., C.J. Lagerkvist and A. Esmat (2021a). Risk perception and determinants in small-and mediumsized agri-food enterprises amidst the COVID-19 pandemic: Evidence from Egypt. Agribusiness, 37: $187-212$.

Hatab, A.A., Z. Liu, A. Naseer and A. Esmat (2021b). Determinants of SARS-CoV-2 Impacts on Small-Scale Commercial Broiler Production Systems in Egypt: Implications for Mitigation Strategies. Animals, 11: 1354. https://doi.org/10.3390/ani11051354

Human Rights Watch (2019). "When We're Dead and Buried, Our Bones Will Keep Hurting”: Workers' Rights Under Threat in US Meat and Poultry Plants. Available at: https://www.hrw.org/report/2019/09/04/when-were-dead-and-buried-our-bones-will-keephurting/workers-rights-under-threat, Accessed June 2, 2020

MALR (2019). The Ministry of Agriculture and Land Reclamation. Annual Bulletin of Indicators of Agricultural Statistics(2019); MALR: Cairo,

Mekled, M.N., H.H. Sharara, A. Galal and A.M. Sayed (2019). Impact of food industry byproducts and wastes on broilers performance. Egypt. Poult. Sci. J., 39: 275-290.

National Farmers Union (NFU) (2020). Coronavirus: what is the impact on the poultry sector? ttps://www.nfuonline.com/news/coronavirus-updates-and-advice/coronavirus-news/coronaviruswhat-isthe-impact-on-the-poultry-sector/\#Demand\%20for\%20poultry\%20products. Accessed June 15, 2020

Sharma, R., A. Shishodia, S. Kamble, A. Gunasekaran and A. Belhadi (2021). Agriculture supply chain risks and COVID-19: mitigation strategies and implications for the practitioners. International Journal of Logistics: Research And Applications.

Tellioglu, I. and P. Konandreas (2017). Agricultural Policies, Trade and Sustainable Development in Egypt; FAO Issue Paper (March 2017). 2017. Available online: http://www.fao.org/3/i7117e/i7117e.pdf (accessed on 9 April 2021).

UNIDO (2020). Agri-Food and COVID-19 in Egypt, Adaptation, Recovery and Transformation- Rapid qualitative assessment.

Uyanga, V.A., O.M. Onagbesan, C.F.I. Onwuka, B. Emmanuel and H. Lon (2021). Coronavirus Disease 2019 (COVID-19) and Poultry Production: Emerging issues in African Countries. World's Poultry Science Journal, 77: 53-174 